\title{
BMJ Open Initial experience using a femtosecond laser cataract surgery system at a UK National Health Service cataract surgery day care centre
}

\author{
Alexander C Day, ${ }^{1,2}$ Sandeep K Dhallu, ${ }^{2}$ Vincenzo Maurino, ${ }^{2}$ Mark R Wilkins ${ }^{2}$
}

To cite: Day AC, Dhallu SK, Maurino V, et al. Initial experience using a femtosecond laser cataract surgery system at a UK National Health Service cataract surgery day care centre. BMJ Open 2016;6: e012078. doi:10.1136/ bmjopen-2016-012078

- Prepublication history for this paper is available online. To view these files please visit the journal online (http://dx.doi.org/10.1136/ bmjopen-2016-012078).

Received 29 March 2016 Revised 22 June 2016 Accepted 7 July 2016

CrossMark

\begin{abstract}
${ }^{1}$ The NIHR Biomedical Research Centre at Moorfields Eye Hospital NHS Foundation Trust and UCL Institute of Ophthalmology, London, UK

${ }^{2}$ Cataract Service, Moorfields Eye Hospital, London, UK
\end{abstract}

Correspondence to Dr Alexander C Day; alex.day@ucl.ac.uk

\section{ABSTRACT}

Objectives: To describe the initial outcomes following installation of a cataract surgery laser system.

Setting: National Health Service cataract surgery day care unit in North London, UK.

Participants: 158 eyes of 150 patients undergoing laser-assisted cataract surgery.

Interventions: Laser cataract surgery using the AMO Catalys femtosecond laser platform.

\section{Primary and secondary outcome measures:}

Primary outcome measure: intraoperative complications including anterior and posterior capsule tears.

Secondary outcome measures: docking to the laser platform, successful treatment delivery, postoperative visual acuities.

Results: Mean case age was $67.7 \pm 10.8$ years (range 29-88 years). Docking was successful in $94 \%$ (148/ 158 cases), and in $4 \%$ (6/148 cases) of these, the laser delivery was aborted part way during delivery due to patient movement. A total of 32 surgeons, of grades from junior trainee to consultant, performed the surgeries. Median case number per surgeon was 3 (range from 1-20). The anterior capsulotomy was complete in $99.3 \%$ of cases, there were no anterior capsule tears $(0 \%)$. There were 3 cases with posterior capsule rupture requiring anterior vitrectomy, and 1 with zonular dialysis requiring anterior vitrectomy (4/148 eyes, $2.7 \%)$. These 4 cases were performed by trainee surgeons, and were either their first laser cataract surgery (2 surgeons) or their first and second laser cataract surgeries (1 surgeon).

Conclusions: Despite the learning curve, docking and laser delivery were successfully performed in almost all cases, and surgical complication rates and visual outcomes were similar to those expected based on national data. Complications were predominately confined to trainee surgeons, and with the exception of intraoperative pupil constriction appeared unrelated to the laser-performed steps.

\section{INTRODUCTION}

Femtosecond laser-assisted cataract surgery offers many potential advantages over manual phacoemulsification cataract surgery including consistent capsulotomy creation, ${ }^{1-3}$ reduced

\section{Strengths and limitations of this study}

- The main strength of this study is that it reports real-world outcomes following installation of a femtosecond laser platform for cataract surgery, and so the results may be more generalisable than data obtained from a controlled trial.

- A limitation of this study is the retrospective design with reliance on surgeons to faithfully record their complications on the electronic medical records system used.

- Another limitation is the relatively small case series size (158 eyes).

effective phacoemulsification time, ${ }^{4}$ lower endothelial cell loss, ${ }^{45}$ and femtosecond laser astigmatic keratotomy. ${ }^{67}$ To date, there is limited data on visual outcomes and surgical complication rates for laser cataract surgery from randomised controlled trials (RCTs), ${ }^{2}{ }^{8-10}$ with that available being predominantly from large comparative case series. ${ }^{11-13}$ A number of large RCTs are currently in progress including the UK National Institute for Health Research (NIHR)-funded FACT trial (Femto Assisted Cataract Trial, ISRCTN77602616), ${ }^{14}$ and the French FEMCAT study. ${ }^{15}$

A number of studies have provided data on the surgical learning curve for laser cataract surgery, ${ }^{11} 12$ 16-18 with outcomes varying by platform and year of development. ${ }^{19} 20$ The Moorfields at St Ann's Hospital cataract surgery facility is the main site of the FACT trial, and is a high-volume National Health Service (NHS) cataract day care unit. The aim of this work is to describe the initial outcomes following installation of a cataract surgery femtosecond laser system at St Ann's Hospital prior to the start of the FACT trial.

\section{METHODS}

This was a retrospective review of cases performed following installation of the Catalys 
Precision Laser system (Abbott Medical Optics, USA), for cataract surgery at Moorfields Eye Unit at St Ann's Hospital, London. Cases were identified from an electronic medical records system (OpenEyes) and the laser usage $\log$ book, and all were performed between February 2015 and April 2015 prior to the start of the FACT trial. During this period, training was available on the Catalys platform by AMO trainers. All surgeons had access to the platform and training, with surgeon grades varying from trainees (ophthalmology specialist trainee years 3-6), fellows, independent non-consultant surgeons and consultants. Specialist trainees were supervised by a consultant ophthalmologist for all cases. The outcomes investigated were successful patient docking to the laser system, completion of the planned laser delivery and intraoperative complications. All postoperative visual acuities were recorded as Snellen and converted to logMAR, with values for counting fingers, hand movements and perception of light, substituted with 2.10, 2.40 and $2.70 \log$ MAR, respectively. ${ }^{21}$

The study was approved by the Clinical Audit unit, research and development department at Moorfields Eye Hospital. Analyses of this type do not require individual ethical permission as they are viewed as audit (see http:// www.hra.nhs.uk/research-community/before-you-apply/ determine-whether-your-study-is-research/). The study was conducted in accordance with the Declaration of Helsinki, and the UK Data Protection Act.

\section{RESULTS}

Over the 10-week period prior to start of the FACT trial, laser cataract surgery was attempted on 158 eyes of 150 patients. Mean case age was $67.7 \pm 10.8$ years. Sixty-seven cases $(42 \%)$ had ocular copathology. Docking was successful in $94 \%$ (148/158 cases), and in $4 \%(6 / 148$ cases) of these, the laser delivery was aborted part way during delivery due to patient movement. Where docking was not possible, patients underwent manual phacoemulsification and IOL implantation with appropriate anaesthesia $(\mathrm{n}=10 ; 6.3 \%)$. All surgeries were single procedures (phacoemulsification and IOL insertion), except one case which was combined phacoemulsification, IOL insertion and trabeculectomy.

A total of 32 surgeons, of grades from junior trainee to consultant, performed the surgeries. Median case number per surgeon during the study period was three (range 1-20). Two surgeons (five and two surgical cases in this series) had previously performed $>200$ laser cataract surgery procedures.

Intraoperative problems of any severity were recorded for 14 cases $(9.6 \%)$. The anterior capsulotomy was complete in $99.3 \%$ of cases. For the one case where it was incomplete, this was in an eye with white/hypermature cataract and required manual completion with capsulorrhexis forceps. Overall, there were no anterior capsule tears. There were three cases with posterior capsule rupture requiring anterior vitrectomy, and one with zonular dialysis requiring anterior vitrectomy (4/148 eyes, $2.7 \%$ ). These four cases were performed by trainee surgeons and were either their first laser cataract surgery (two surgeons who performed a total of two and 12 laser cataract surgeries in this series); or their first and second laser cataract surgeries (one surgeon who performed a total of six laser cataract surgeries in this series). Table 1 shows the specific details for each case.

Mean postoperative UDVA was 0.26 logMAR (SD 0.34) and postoperative best measured visual acuity (better of UDVA or pinhole) was $0.14 \log$ MAR (SD 0.31) at mean 26 days follow-up. Thirty-one per cent of cases achieved $0.0 \log$ MAR or better UDVA.

\section{DISCUSSION}

This manuscript describes the outcomes following installation of the AMO Catalys femtosecond laser cataract

Table 1 Intraoperative problems

\begin{tabular}{|c|c|c|}
\hline Complication & Number (\%) & Case-specific details \\
\hline Incomplete anterior capsulotomy & $1(0.7)$ & $\begin{array}{l}\text { 1: Incomplete in white/hypermature cataract, completed with } \\
\text { forceps. }\end{array}$ \\
\hline Anterior capsule tear & $0(0)$ & - \\
\hline Posterior capsule tear with vitreous loss & $3(2.0)$ & $\begin{array}{l}1(0.7 \%) \text { : Trainee surgeon, dense cataract with small pupil, small } \\
\text { anterior capsulotomy made and enlarged manually at start of case, } \\
\text { posterior capsule tear during lens removal. } 2(1.4 \%) \text { : Trainee } \\
\text { surgeon, posterior capsule tear during lens fragment removal. }\end{array}$ \\
\hline Posterior capsule tear, no vitreous loss & $0(0)$ & - \\
\hline Zonular dialysis with vitreous loss & $1(0.7)$ & Trainee surgeon, anterior vitrectomy, IOL to sulcus. \\
\hline Zonular dialysis, no vitreous loss & $0(0)$ & - \\
\hline IOL issues & $1(0.7)$ & IOL scratch seen post-IOL injection into capsular bag. \\
\hline Iris problems & $7(4.7)$ & $\begin{array}{l}3(2.0 \%) \text { : intraoperative floppy iris syndrome associated with } \\
\alpha \text {-blocker use. } \\
4(2.7 \%) \text { : pupil down during procedure, requiring iris hooks in three } \\
\text { cases. }\end{array}$ \\
\hline Phacoemulsification platform issues & $1(0.7)$ & Hand piece fault, swapped during case. \\
\hline
\end{tabular}


surgery platform in a UK National Health Service cataract surgery day care unit, and includes surgeons of all grades. Overall, we found $99.3 \%$ of anterior capsulotomies to be complete, there were no cases of anterior capsule tears, and there was a vitreous loss rate of $2.7 \%$. Expected posterior capsule rupture and/ or vitreous loss rates from the UK RCOphth National Ophthalmology Database report of outcomes from 28 NHS Hospital Trusts were $1.95 \%$ overall and $2.51 \%$ for cases with any ocular copathology. ${ }^{21}$ Of note, $42 \%$ eyes in our series had ocular copathology, and this proportion is higher than in the recent RCOphth NOD analysis where the corresponding value was $37 \%$. This may, in part, explain the higher complication rate, in addition to that due to the surgical learning curve for transition to laser cataract surgery. While it is not possible to separate complications that are directly attributable to the use of the laser platform, based on the intraoperative stages at which these occurred, they appear unlikely to be directly related to the use of the Catalys system as, for example, there were no posterior capsule tears resulting from an anterior capsule rip. Furthermore, all cases in which a posterior capsule tear/vitreous loss did occur, were higher than average risk cases due to the presence of one or more independent risk factors for posterior capsule rupture. $^{22}$ In this study, $31 \%$ eyes achieved a postoperative best-measured visual acuity of $0.0 \operatorname{logMAR}$ or better, and the corresponding value reported in the RCOphth NOD was $24 \%$ eyes overall achieved a postoperative best measured visual acuity of $0.0 \log$ MAR or better. Overall, the surgical complication rates and visual outcomes show that the transition to laser-assisted cataract surgery in a UK NHS environment appears safe despite the learning curve.

In this series, we found that docking was not possible in $6 \%$ of cases, and that in $4 \%$ of cases where successful docking was made, the laser delivery was abandoned part way during delivery. Naturally, one would expect these values to be lower outside the learning curve, however, this does emphasise that docking and laser delivery appears acceptable to almost all patients, despite limited previous experience for the vast majority of surgeons within this series.

Of note, the four cases with vitreous loss were either trainees' first laser-assisted cataract surgery (two surgeons), or their first and second laser-assisted cataract surgeries (one surgeon). A number of studies have provided data on the surgical learning curve for laser cataract surgery, ${ }^{11} 12$ 16-18 with laser platforms having also undergone considerable software and hardware development over the past few years. ${ }^{2324}$ A large case series of 1852 operations using the AMO Catalys platform report an anterior capsule tear rate of $1.84 \%$ and posterior capsule tear rate of $0.43 \% .{ }^{13}$ For trainee surgeons, intraoperative and postoperative complication rates of laser-assisted cataract surgery are thought to be similar to those of manual cataract extraction. ${ }^{18}$ Data from a small series on trainee surgeons' initial supervised use of the Alcon LenSx platform reported a successful docking rate of $97.6 \%$ and posterior capsule tear rate of $0 \%$
$(0 / 62$ cases $) .{ }^{17}$ In a recent report of the first 2 years of experience using the Bausch and Lomb Victus platform, the posterior capsule tear rate was low even within the learning curve $\left(0.3 \%, 3 / 1105\right.$ events overall) ${ }^{11}$

Interestingly, we found the vast majority of intraoperative complications to be iris problems, with the pupil coming down in three $(2.0 \%)$ cases, such that iris hooks were required to complete the respective cases. A recent comparative series investigating pupil diameter before and after laser cataract surgery reported that laser pretreatment induced significant pupillary miosis with the pupil diameter falling below $5 \mathrm{~mm}$ in $4.0 \%$ of cases. ${ }^{25} \mathrm{In}$ a series of 1500 laser cataract operations, the intraoperative pupil constriction rate was reduced from $9.5 \%$ in the first 200 cases to $1.2 \%$ for the latter 1300 cases when an additional one drop of $10 \%$ phenylephrine was given after the laser procedure. ${ }^{12}$ The authors also noted that factors such as platform evolution, which shortened overall procedure time, and more efficient scanning patterns that reduced the required delivered energy, may also have been partly attributable. ${ }^{12}$

Based on our experience and the published literature, emphasis on the following changes to clinical practice appears helpful to facilitate the conversion to laserassisted cataract surgery:

1. Careful case selection. This covers multiple areas including expected patient cooperation ${ }^{16}$ to dilated pupil size. For the latter, while some lasers have automatic capsulotomy diameter reduction if the pupil is smaller than that required for the programmed capsulotomy size, there is little point proceeding to make a capsulotomy that subsequently needs enlarging at the beginning of the procedure (with the possible exception of that for intumescent white cataracts where creating a laser mini capsulotomy has reported to be effective). ${ }^{26}$

2. To administer additional mydriatic eye drops following the laser delivery to minimise the risk of intraoperative pupil constriction. ${ }^{12}$

3. Confirming the capsulotomy is complete ('free floating') without any adhesions, which if present, can be successfully managed to prevent extension to a capsular tear. ${ }^{27}$

4. Careful hydrodissection to reduce any likelihood of capsular block and associated posterior capsule rupture. ${ }^{28}$

The main limitations of this study are its retrospective design with reliance on surgeons to faithfully record their complications on the electronic medical records system used, and also the relatively small case series size.

In conclusion, despite the learning curve, docking and laser delivery were successfully performed in almost all cases, and surgical complication rates and visual outcomes were similar to those expected based on national data. Complications were predominately confined to trainee surgeons, and with the exception of intraoperative pupil constriction appeared unrelated to the laserperformed steps. 
Twitter Follow Mark Wilkins at @wilkoman

Contributors ACD was responsible for the study concept. All authors made substantial contributions to the design of the study. ACD drafted the manuscript and all authors provided critical review and approved the final manuscript.

Funding ACD was supported by the National Institute for Health Research (NIHR) Biomedical Research Centre based at Moorfields Eye Hospital NHS Foundation Trust, and UCL Institute of Ophthalmology.

Competing interests None declared.

Provenance and peer review Not commissioned; externally peer reviewed.

Data sharing statement No additional data are available.

Open Access This is an Open Access article distributed in accordance with the Creative Commons Attribution Non Commercial (CC BY-NC 4.0) license, which permits others to distribute, remix, adapt, build upon this work noncommercially, and license their derivative works on different terms, provided the original work is properly cited and the use is non-commercial. See: http:// creativecommons.org/licenses/by-nc/4.0/

\section{REFERENCES}

1. Mastropasqua L, Toto L, Calienno R, et al. Scanning electron microscopy evaluation of capsulorhexis in femtosecond laser-assisted cataract surgery. J Cataract Refract Surg 2013;39:1581-6.

2. Mastropasqua L, Toto L, Mattei PA, et al. Optical coherence tomography and 3-dimensional confocal structured imaging system-guided femtosecond laser capsulotomy versus manual continuous curvilinear capsulorhexis. J Cataract Refract Surg 2014;40:2035-43.

3. Day AC, Gartry DS, Maurino V, et al. Efficacy of anterior capsulotomy creation in femtosecond laser-assisted cataract surgery. J Cataract Refract Surg 2014;40:2031-4.

4. Abell RG, Kerr NM, Vote BJ. Toward zero effective phacoemulsification time using femtosecond laser pretreatment. Ophthalmology 2013;120:942-8.

5. Conrad-Hengerer I, Al Juburi M, Schultz T, et al. Corneal endothelia cell loss and corneal thickness in conventional compared with femtosecond laser-assisted cataract surgery: three-month follow-up. J Cataract Refract Surg 2013;39:1307-13.

6. Day AC, Lau NM, Stevens JD. Nonpenetrating femtosecond laser intrastromal astigmatic keratotomy in eyes having cataract surgery. $J$ Cataract Refract Surg 2016;42:102-9.

7. Day AC, Stevens JD. Stability of keratometric astigmatism after non-penetrating femtosecond laser intrastromal astigmatic keratotomy performed during laser cataract surgery. J Refract Surg 2016;32:152-5.

8. Mastropasqua L, Toto L, Mastropasqua A, et al. Femtosecond laser versus manual clear corneal incision in cataract surgery. J Refract Surg 2014;30:27-33.

9. Conrad-Hengerer I, Hengerer $\mathrm{FH}, \mathrm{Al}$ Juburi $\mathrm{M}$, et al. Femtosecond laser-induced macular changes and anterior segment inflammation in cataract surgery. J Refract Surg 2014;30:222-6.

10. Conrad-Hengerer I, Al Sheikh M, Hengerer FH, et al. Comparison of visual recovery and refractive stability between femtosecond laserassisted cataract surgery and standard phacoemulsification: six-month follow-up. J Cataract Refract Surg 2015;41:1356-64.
11. Chee SP, Yang Y, Ti SE. Clinical outcomes in the first two years of femtosecond laser-assisted cataract surgery. Am J Ophthalmol 2015;159:714-19.

12. Roberts TV, Lawless M, Bali SJ, et al. Surgical outcomes and safety of femtosecond laser cataract surgery: a prospective study of 1500 consecutive cases. Ophthalmology 2013;120:227-33.

13. Abell RG, Darian-Smith E, Kan JB, et al. Femtosecond laser-assisted cataract surgery versus standard phacoemulsification cataract surgery: outcomes and safety in more than 4000 cases at a single center. J Cataract Refract Surg 2015;41:47-52.

14. Day AC, Burr JM, Bunce C, et al. Randomised, single-masked non-inferiority trial of femtosecond laser-assisted versus manual phacoemulsification cataract surgery for adults with visually significant cataract: the FACT trial protocol. BMJ Open 2015;5: e010381.

15. Schweitzer C, Hayes N, Brezin A, et al., FEMCAT Study. Re: Abell et al.: cost-effectiveness of femtosecond laser-assisted cataract surgery versus phacoemulsification cataract surgery (Ophthalmology 2014;121:10-6). Ophthalmology 2014;121:e53-54.

16. Nagy ZZ, Takacs Al, Filkorn T, et al. Complications of femtosecond laser-assisted cataract surgery. J Cataract Refract Surg 2014;40:20-8

17. Hou JH, Prickett AL, Cortina MS, et al. Safety of femtosecond laser-assisted cataract surgery performed by surgeons in training. $J$ Refract Surg 2015;31:69-70.

18. Cohen $\mathrm{MN}$, Intili A, Ni N, et al. Femtosecond laser-assisted cataract surgery in residency training. Curr Opin Ophthalmol 2015;26:56-60.

19. Bali SJ, Hodge C, Lawless M, et al. Early experience with the femtosecond laser for cataract surgery. Ophthalmology 2012;119:891-9.

20. Abell RG, Kerr NM, Vote BJ. Femtosecond laser-assisted cataract surgery compared with conventional cataract surgery. Clin Experiment Ophthalmol 2013;41:455-62.

21. Day AC, Donachie PH, Sparrow JM, et al. Royal College of Ophthalmologists' National Ophthalmology Database. The Royal College of Ophthalmologists' National Ophthalmology Database study of cataract surgery: report 1 , visual outcomes and complications. Eye (Lond) 2015;29:552-60.

22. Narendran $\mathrm{N}$, Jaycock $\mathrm{P}$, Johnston $\mathrm{RL}$, et al. The Cataract National Dataset electronic multicentre audit of 55,567 operations: risk stratification for posterior capsule rupture and vitreous loss. Eye (Lond) 2009;23:31-7

23. Roberts TV, Lawless M, Chan CC, et al. Femtosecond laser cataract surgery: technology and clinical practice. Clin Experiment Ophthalmol 2013;41:180-6.

24. Roberts TV, Lawless M, Sutton G, et al. Anterior capsule integrity after femtosecond laser-assisted cataract surgery. J Cataract Refract Surg 2015;41:1109-10.

25. Diakonis VF, Yesilirmak N, Sayed-Ahmed IO, et al. Effects of femtosecond laser-assisted cataract pretreatment on pupil diameter: a comparison between three laser platforms. J Refract Surg 2016:32:84-8.

26. Schultz T, Dick HB. Laser-assisted mini-capsulotomy: a new technique for intumescent White cataracts. J Refract Surg 2014;30:742-5

27. Arbisser LB, Schultz T, Dick HB. Central dimple-down maneuver for consistent continuous femtosecond laser capsulotomy. J Cataract Refract Surg 2013;39:1796-7.

28. Roberts TV, Sutton G, Lawless MA, et al. Capsular block syndrome associated with femtosecond laser-assisted cataract surgery. J Cataract Refract Surg 2011;37:2068-70. 